\title{
Complete AVB Initially Complicating STEMI in Post Percutaneous Revascularization: Case Report
}

\author{
Larsen Clarck MOUMPALA ZINGOULA ${ }^{1 *}$, Rachida NHIRI ${ }^{1}$, Mohamed Bensasser ${ }^{1}$, Hassan \\ Fadoum ${ }^{1}$, Fatima Zahra Benmessaoud ${ }^{2}$, Latifa Oukerraj ${ }^{3}$, Ibtissan Fellat ${ }^{4}$ and Mohamed Cherti ${ }^{5}$ \\ ${ }^{1}$ Department of Cardiology B, Morocco \\ ${ }^{2}$ Cardiology specialist, Catheterization, Morocco
}

${ }^{3}$ Professor of Cardiology, Catheterization, Morocco

${ }^{4}$ Professor of Cardiology, Rhythmology, Morocco

${ }^{5}$ Professor of Cardiology, Head of Department of Cardiology, Morocco

*Corresponding author: Larsen Clarck MOUMPALA ZINGOULA, Department of Cardiology B, Ibn Sina University Hospital Center,

Mohammed V University of Rabat, Tabriquet Salé-Rabat, postal code 11000, Morocco

\section{ARTICLE INFO}

Received: 蔧 May 20, 2021

Published: 幽 June 02, 2021

Citation: Larsen Clarck M, Rachida NHIRI , Mohamed B, Hassan F, Fatima Zahra Benmessaoud, et al., Complete AVB Initially Complicating STEMI in Post Percutaneous Revascularization: Case Report. Biomed J Sci \& Tech Res 36(2)-2021. BJSTR. MS.ID.005821.

\section{ABSTRACT}

Conduction disturbances complicating acute myocardial infarction with persistent ST segment elevation are common, especially those of high degree in previous myocardial infarctions. Do these complications occur in the acute phase, before revascularization, with a poor prognosis immediately justifying myocardial reperfusion as well as the placement of an electro systolic training lead. However, their absence before revascularization to occur in post percutaneous reperfusion by angioplasty with placement of an active stent on the culprit artery, with an increase in the ST elevation, is unprecedented and raises as many questions as possible whereas the Stent in place remains permeable. We report the case of a patient presenting, initially, a 3rd degree atrioventricular block after percutaneous revascularization of an ST + extended anteriorly by angioplasty and placement of an active stent on the anterior interventricular coronary artery permeable after a second post-critical coronary angiography.

Keywords: Anterior Myocardial Infarction; 3rd Degree Atrioventricular Block; Cardiac Arrest; Anterior Interventricular Artery; Electro systolic Training Lead; Fibrinolysis; Coronary Vasospasm

\section{Introduction}

Complete or third degree atrioventricular block (cAVB), defined by the complete and permanent interruption of the transmission of atrial impulses to the ventricles [1,2] is one of the early and relatively frequent complications of myocardial necrosis whose pathophysiology and the course differs depending on the seat of the infarction; indeed, AVB always shows anatomically extensive infarcts, the mortality of which from previous infarctions complicated by AVB remains considerable (> 60\%) in the absence of early revascularization $[3,4]$. This complication, very common before the era of revascularization, occurs in the acute phase.
Their early installation in post reperfusion of an extensive anterior myocardial infarction is unprecedented and has a particular aspect which justifies our review. We report a case of complete atrioventricular block occurring initially after Percutaneous Revascularization (PR) of extensive anterior ST + (STEMI-EA).

\section{Clinical Case}

This is a 51-year-old patient, chronic active smoker and diabetic discovered in hospital, with no history; he presented with an inaugural retrosternal infarction stabbing chest pain, radiating to the upper left limbs for which he consulted at $\mathrm{H} 9$ in 
the Emergency Department of the Ibn Sina University Hospital. On clinical examination, the eupneic patient was unwell with a good hemodynamic state, as for his electrocardiogram at $\mathrm{H} 9$, we note a super shift of the ST segment in the extended anterior (Figures 1), from which he benefited from thrombolysis with success criteria, and the next day

a) A biological balance made of troponin $>50,000 \mathrm{ng} / \mathrm{ml}$, potassium at $5 \mathrm{mmol} / \mathrm{l}$ of a DFG at $66 \mathrm{ml} / \mathrm{min} / 1.73 \mathrm{~m}^{2}$.

b) A trans thoracic Doppler echocardiography which shows lesions of disturbed kinetics.

c) A coronary angiogram showing a sub-occluded lesion of the average anterior interventricular artery (AIV) having undergone angioplasty and placement of an active stent.
The immediate evolution, 2 hours later, was marked by the inaugural onset of a complete AVB and a cardiac arrest by asystole, recovered by resuscitation measure, followed by 4 episodes of cardiac pause with an increase in the elevation of the ST segment in the same territory (Figures 2).

d) He underwent a second coronary angiography showing an active stent in place and permeable, without other culpable lesions.

e) Then the setting of a provisional electro systolic training lead.

The medical consequences are marked by a spontaneous recovery after 48 hours of return to sinus rhythm. The patient is declared discharged, the course of which is marked by the sudden onset of cardiac arrest at home after 3 weeks.

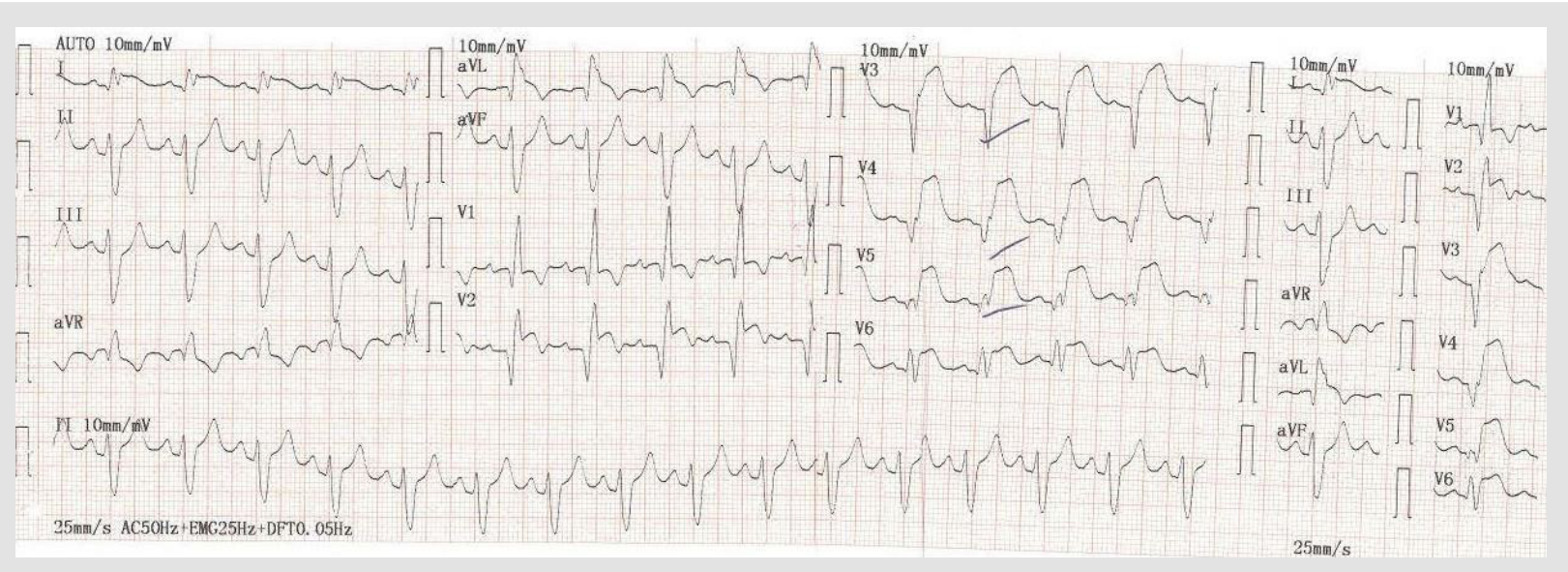

Figure 1: Patient admitted for infarctoid chest pain to Avicenna's Emergency Department, at H8, related to an extensive anterior ST + thrombolysed with successful Metalysis at H9: pain sedation and regression of ST + amplitude. And his troponin was> 50,000 $\mathrm{ng} / \mathrm{ml}$.

Note: Day 1: ST segment shift in extended anterior before thrombolysis, before percutaneous coronary revascularization.

\section{Discussion}

The vascularization of the cardioverter system, in particular that of the atrioventricular bundle and its branches is provided by the artery of the atrioventricular node and an anterior septal artery (usually the second). This accounts for the conduction disturbances that are observed during certain myocardial infarctions [5]. The blocks of anterior and / or septal infarctions, related to an attack of the AIV, are located low, secondary to the involvement of the 2 branches or the 3 fascicles of the bundle of His. However, this is not immediately simultaneous, hence the usual precession of bundle branch block or bifascicular, on atrioventricular block [3]. According to our research, this unprecedented case is the first patient to initially develop cAVB after PR from STEMI-EA. In all the studies reviewed, there is unanimity that the prognosis for mortality from complicated MI of cAVB is poor, whether it occurs in the acute phase before or after the PRC era. Authors who have performed studies on cAVB complicating MI, we cite UJ Gang, Hymie H, Harpaz D, Nguyen [6-9] have worked on what appear to be patients with cAVB present during the early phase of an MI even before revascularization either by thrombolysis or by PR to judge the effectiveness of the two methods on the patient's prognosis. In the course of our research, we issued opinions, possible hypotheses, which could explain, if applicable, our patient:

a) Either by stenosis of the Stent with spontaneous reperfusion by fibrinolysis which allows the lysis of the fibrinoerythro-platelet clot, and the maintenance of vascular permeability $[10,11]$ (The in situ formation of a coronary thrombus can lead to the occlusion responsible for 'an MI, followed by spontaneous lysis of the thrombus, which may explain the discovery of normal angiography [12]); which is unlikely given that the patient received a $600 \mathrm{mg}$ bolus of Clopidogrel, just prior to PR, to prevent activation of platelets by inhibiting adenosine Di-phosphate;

b) Or by prolongedvasospasm of the anterior interventricular artery [11-18].

In these two hypotheses, the patient would undergo a second MI in the anterior extensive with ischemia of the cardionector system. This would justify the electrical occurrence of a cAVB, then the enhancement of his STEMI in the same territory followed by cardiac arrest due to asystole (Figure 3). 


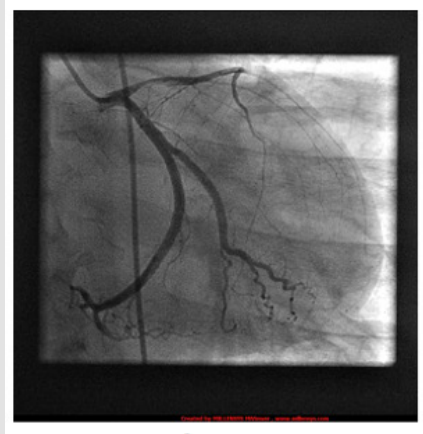

a

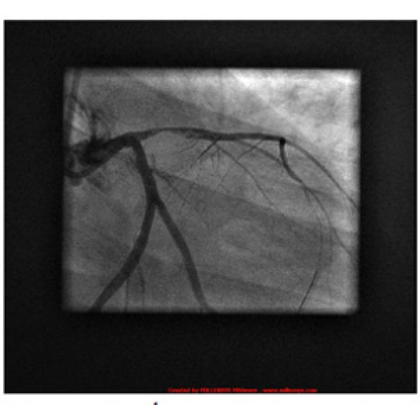

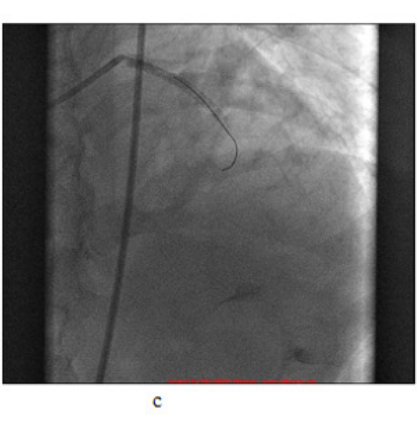

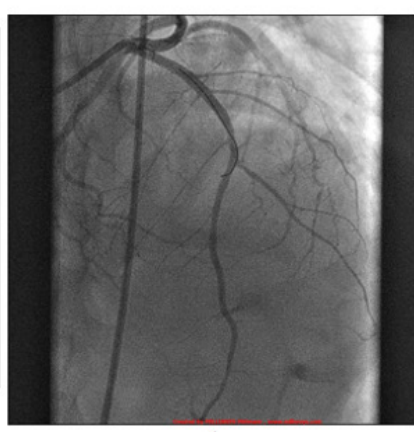

Figure 2:

a. Figure b: Coronary angiography image 1: sub-occlusion of the proximal anterior interventricular artery and

b. Figure d: Coronary angiography image 2: Active permeable stent in place on the proximal anterior interventriventricular artery.

Note: Day 2: the next day, he was transferred to Cardiology B, where he received an ETT, followed by a coronary angiography at 1:30 p.m. Objectifying a sub-occluded proximal VIA. He was then transferred to the Intensive Care Unit of Cardiology B at 2:50 p.m.

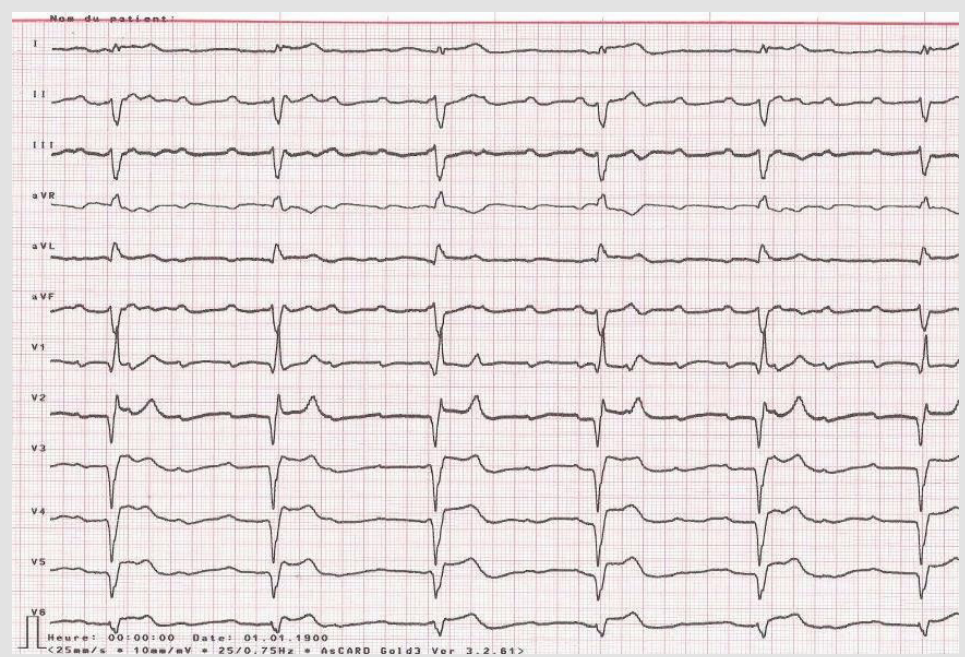

Figure 3: Inaugural complete AVB occurring 2 hours after coronary angiography revascularization.

Note: Day 2: At 4 p.m., the patient under medical scope switches to complete AVB.

The pathophysiological mechanisms of coronary spasm result from endothelial dysfunction and hyperactivity of smooth muscle cells from endogenous (acetylcholine, catecholamines, serotonin, histamine, etc.) or exogenous stimuli having a vasoconstrictor effect (tobacco, cocaine, etc.) [13]. The population is younger than in classic coronary patients, with a predominance of men, whose main cardiovascular risk factor incriminated in this pathology is active smoking [14]. Studies have assessed the association of clinical risk associated with factors with induction of coronary artery spasm. It emerges that smoking was a risk factor for coronary artery spasm in numerous studies [15]: this is the cardiovascular profile of our patient whose development, after recovered cardiac arrest, was marked by spontaneous recovery of his condition sinus heart rate after h.m (Figure 6) However, the occurrence of the patient's sudden death at home, after three weeks of his discharge after returning to sinus rhythm, suggests a recurrence of the same clinical picture during his stay (Figures $4 \& 5$ ). It is believed that in the acute phase of an MI even in post revascularization, not everything is won. However, continued clinical monitoring in a cardiology intensive care unit is the rule. We also insist on the fact that patients prone to this complication of BAVc occurring before or after percutaneous revascularization of a previous ACS ST + , should benefit from the implantation of a pacemaker in prevention of recurrence of conduction disorder and cardiac asystole, considering the very high risk of mortality [19] (Table 1). 


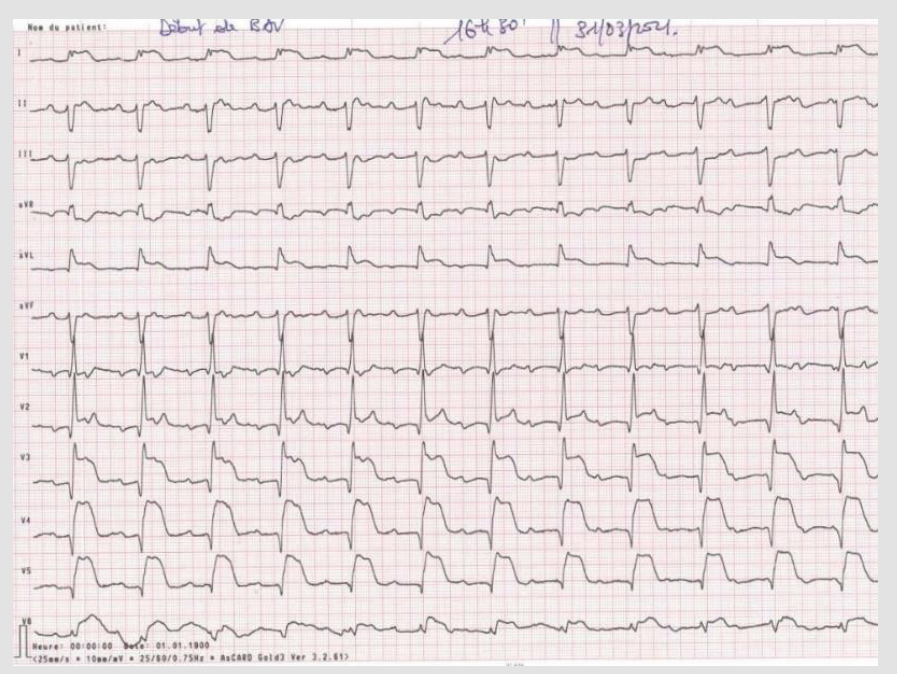

Figure 4: Inaugural full AVB with increased ST segment elevation post-revascularization, 3 hours after coronary angiography. Note: $6 \mathrm{~h}$, then he modifies his extended anterior ST + segment by increasing amplitude during his complete AVB with clinically hemodynamic instability and altered consciousness.

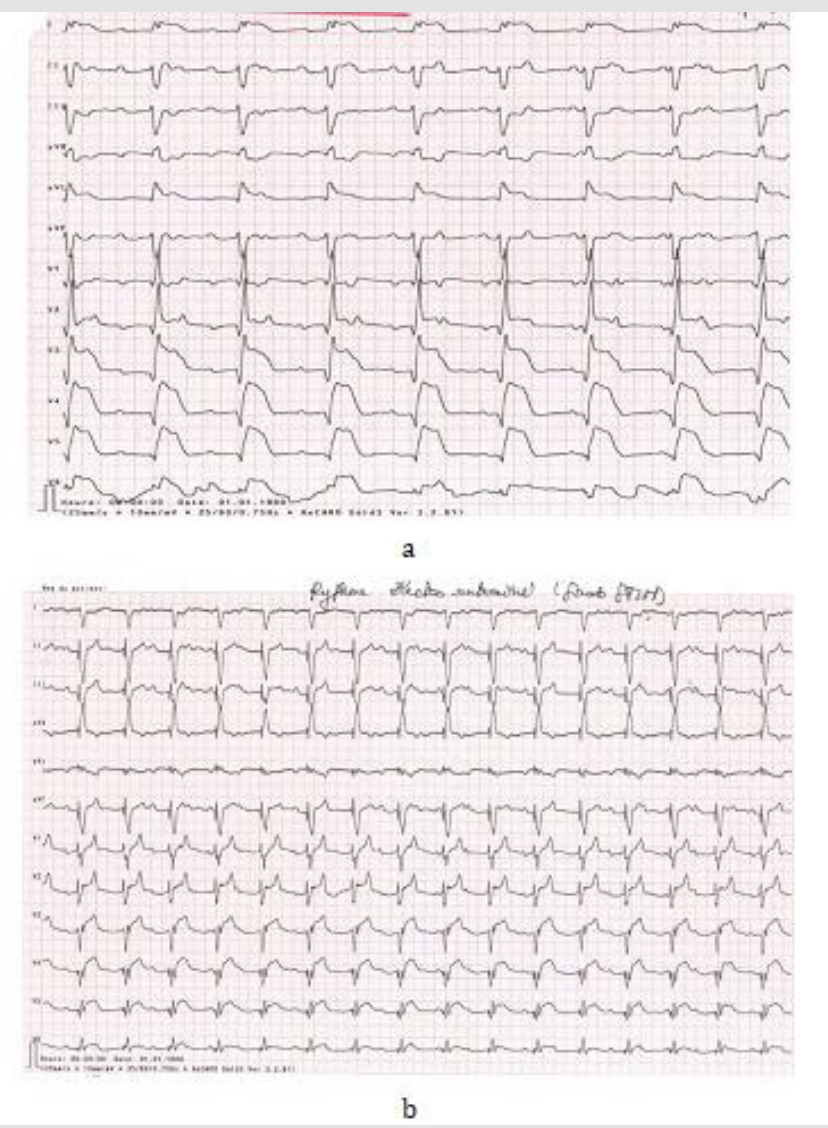

\section{Figure 5:}

a. Post cardiac arrest recovered, persistence of complete AVB with shifting of the ST segment, 3 hours after coronary angiography. b. Electro rhythm trained by the Electro-systolic Training Probe probe.

Note: 5:00 p.m., cardiac arrest from asystole ensues requiring resuscitation by cardio thoracic massage for 10 to 15 minutes with the use of adrenaline and other drugs. The patient is then taken to the Catheterization room for a second coronary angiography by the same day team. Second coronary angiography showing a stent in place, permeable with good TIMI 3 . Then installation of an Electro-systolic Training Probe by the Rhythmology team. 


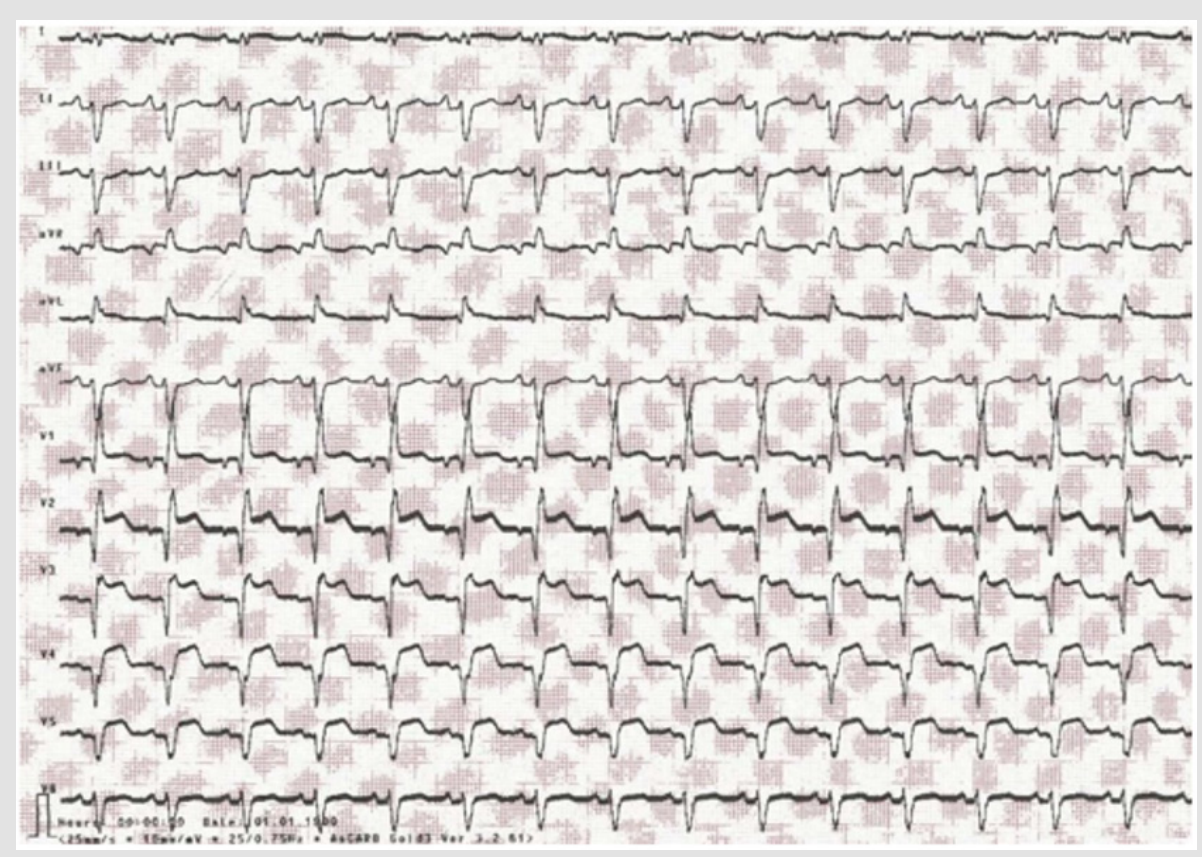

Figure 6: Return to sinus rhythm after $48 \mathrm{~h}$, with good clinical and hemodynamic and rhythmic evolution.

Note: Day 5: Return to sinus rhythm before discharge from the hospital.

Table 1.

\section{Atrioventricular Blocks of the Acute Phase of the Previous Infarction}

Responsible artery : anterior interventricular (after septals)

Mechanism : branch ischemia or necrosis

Headquarters : infrahissien

Block type : $2^{\text {nd }}$ degree Mobitz II ; $3^{\text {rd }}$ degree

\section{Exhaust rhythm :}

- Wide QRS; often $<30 \mathrm{bpm}$

- Unstable with risk of heart failure

Method of installation : brutal, preceded by the appearance of bundle branch block

Evolution : not always regressive ; sequellar brach blocks

Treatment : temporary or definitive electro-systolic training

Morttality : high due to myocardial infarction

\section{Conclusion}

High-degree conduction disorders, such as complete atrioventricular block, are among the early complications of anterior myocardial infarction indicating a poor prognosis, the urgency of which would be immediate revascularization, as well as the initiation of instead of an electro systolic training probe or even a pacemaker. It is therefore unprecedented to see such a conduction disorder occurring, in the first place, hours after percutaneous revascularization, the causes of which are still uncertain.

\section{References}

1. Pierre Taboulet (2018) ECG de A à Z. Edition 2018, Maloine.
2. Pierre Taboulet (2014) Blocs sinoauriculaires et auriculoventriculaires. Urgences SFMU.

3. A Leenhardt, C Sebag, F Extramiana, V Algalarrondo (2012) L Essentiel en RYTHMOLOGIE. In: A Leenhardt, C Sebag, F Extramiana, V Algalarrondo (Eds.)., Lavoisier SAS, France.

4. Jesse J Corry, Andrew M Naidech (2013) Cardiovascular Monitoring and Complications. Neurocritical Care Society Practice Update

5. C Latremouille, F Lintz (2005) Anatomie du cœur. Elsevier Masson.

6. UJ Ortved Gang, A Hvelplund (2012) High-degree atrioventricular block complicating ST-segment elevation myocardial infarction in the era of primary percutaneous coronary intervention. ESC 14(11): 1639-1664.

7. Hymie H, Chera Cristina A, Mitre Justin Nealis, Alex Mironov Adam, S Budzikowski (2018) Frequency of Complete Atrioventricular Block Complicating ST-Elevation Myocardial Infarction in a Patient Undergoing 
Primary Percutaneous Coronary Intervention. Cardiology 140(3): 146151.

8. Harpaz D, Behar S, Gottlieb S, Boyko V, Kishon Y (1999) Complete atrioventricular block complicating acute myocardial infarction in the thrombolytic era. SPRINT Study Group and the Israeli Thrombolytic Survey Group. Secondary Prevention Reinfarction Israeli Nifedipine Trial. J Am Coll Cardiol 34(6): 1721-1728.

9. Hoa L Nguyen, Darleen Lessard (2008) Thirty-year trends (1975-2005) in the magnitude and hospital death rates associated with complete heart block in patients with acute myocardial infarction: A populationbased perspective. American Heart Journal August 156(2): 227-233.

10. Chloé James. Physiologie del'hémostase. MCU-PH, Laboratoire d'hématologie, Hôpital Haut Levêque.

11. JY Artigou, JJ Monsuez (2020) Cardiologie et Maladies Vasculaires. Société Française de Cardiologie. Offre premium. In: JY Artigou, JJ Monsuez (Eds.)., (2020 ${ }^{\text {th }}$ Edn.)., Elsevier, USA.

12. Kardasz I, De Caterina R (2007) Myocardial infarction with normal coronary arteries:a conundrum with multiple aetiologies and variable prognosis: an update. JIntern Med 261(4): 330-348.

\section{ISSN: 2574-1241}

DOI: 10.26717/BJSTR.2021.36.005821

\section{Larsen Clarck MOUMPALA ZINGOULA. Biomed J Sci \& Tech Res}

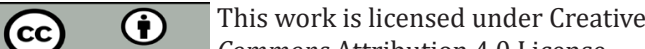

Submission Link: https://biomedres.us/submit-manuscript.php
13. Lanza GA, Careri G, Crea F (2011) Mechanisms of coronary artery spasm. Circulation 124(16): 1774-1782.

14. Takagi Y (2013) Prognostic stratification of patients with vasospastic angina: a comprehensive clinical risk score developed by the Japanese Coronary Spasm Association. J Am Coll Cardiol 62(13): 1144-1153.

15. Beltrame JF (2016) The who, what, why, when, how and where of vasospasticangina. Circ J 80(2): 289-298.

16. Benamer H (2019) Langor spastique : une pathologie sousdiagnostiquée. Ann Cardiol Angeiol (Paris). 68(5).

17. Picard F (2019) Vasospastic angina: A literature review of current evidence. Arch Cardiovasc Dis 112(1): 44-55.

18. D Attias, N Lellouche (2018) Cardiologie vasculaire. In: D Attias, N Lellouche (Eds.)., ( $8^{\text {th }}$ Edn.)., Cardiologie.

19. Borja Ibanez, Stefan James (2018) Guidelines for the management of acute myocardial infarction in patients presenting xith ST-segment elevation. 2017 ESC; EHJ 39: 119-177.

$\begin{array}{ll}\text { BIOMEDICAL } & \text { Assets of Publishing with us } \\ \text { RESEARCHES } & \text { Global archiving of articles } \\ & \text { - Immediate, unrestricted online access } \\ & \text { - }\end{array}$

